\title{
Electronic Health Records and Patient Empowerment in US: from the Legal Perspective
}

\author{
Kai Liu ${ }^{1}$ \\ ${ }^{1}$ Faculty of International and European Law, School of Law, Utrecht University, Utrecht, the Netherlands \\ Correspondence: Kai Liu, Faculty of International and European Law, School of Law, Utrecht University, Utrecht, the \\ Netherlands.
}

Received: September 2, 2016

Accepted: September 12, 2016

Available online: September 13, 2016

doi:10.11114/ijsss.v4i10.1877

URL: http://dx.doi.org/10.11114/ijsss.v4i10.1877

\begin{abstract}
Objective: to examine the American electronic health records from a legal perspective. Results: the EHR system presents characteristics from the five aspects: accessibility, coordination, sustained care, decision making, and privacy. Conclusion: The US law in the field of Patient-Centered Health Information Technology has many elements of patient empowerment. There is still a gap between the system is and the system should be. It is found that first, A mandatory adoption of EHR system; second, privacy should be further ensured; and third, the accessibility should be further improved.
\end{abstract}

Keywords: Electronic Health Records, Health Law, Patient's Health Information

\section{Introduction}

A consensus is made that the use of health information technology should lead to more efficient, safer, and higher-quality care (Ciampa \& Revels, 2009). According to Ciampa and Revels, the Health Information Technology (HIT) --- though described in many ways: as a framework for managing health information, as a mechanism to improve patient care, and as an enabler of patient care coordination--- is the application of the information technology to the healthcare industry. In this context, the Patient-centered Health Information Technology (PCHIT) are defined as the HIT application systems that enable a partnership among practitioners, patients, and their families (when appropriate) to ensure that procedures and decisions respect patients' needs and preferences (Demiris et al.,2008; Krist \& Woolf, 2011; Rittenhouse \& Shortell, 2009).

\section{Electronic Health Records Legal System}

Differing and conflicting state privacy laws led to enactment of the 1996 Health Insurance Portability and Accountability (HIPAA) Act of 1996. More than a decade later, the Health Information Technology for Economic and Clinical Health Act (HITECH) Act of 2009 amended HIPAA (Hiller et al., 2011). Although HITECH could be better understood as an essential foundation for our broader efforts to restructure health care delivery, it may be also viewed to a narrower sphere, as legislation to stimulate the adoption of HIT (Buntin et al., 2010). This Act has made the promotion of a national, interoperable HIT system a priority (Jha et al., 2009). The Act define HIT as hardware, software, integrated technologies or related licenses, intellectual property, upgrades, or packaged solutions sold as services that are designed for or support the use by health care entities or patients for the electronic creation, maintenance, access, or exchange of health information (TITLE XXX (5) of the (HITECH) Act of 2009). That law contains provisions to (1) improve quality of care through expanded measurement and reporting; (2) reduce costs by introducing new models of payment for services and improving efficiency of care delivery and administrative processes; and (3) improve access to care and broaden insurance coverage. In the field of electronic health records, the 2009 Act charged the Office of the National Coordinator (ONC) and Centers for the Medicare and Medicaid Services (CMS) with defining national electronic health records meaningful use (MU) objectives and measures (Subtitle A-Medicare Incentives of the HITECH Act of 2009).

An important form a HIT as the electronic health records (EHR) is slowly adopted by the US health care providers despite of the broad consensus on the potential benefits of this HIT form (Jha et al., 2009). However, due to the Act's express goal setting: the utilization of an electronic health record for each person in the United States by 2014 (Article 11 of Subtitle A-Promotion of Health Information Technology of Title 30 - Health Information Technology And 
Quality), and more over the corresponding mandatory measures to carry the goal out: (1) the required level of Federal funding;(2) expectations for regional, State, and private investment;(3) the expected contributions by volunteers to activities for the utilization of such records; and (4) the resources needed to establish a HIT workforce sufficient to support this effort (including education programs in medical informatics and health information management). Furthermore, the HIECH Act mandates EHR include patient demographic and clinical health information, such as medical history and problem lists; and be capable to: (1) provide clinical decision support; support physician order entry; (2) capture and query information relevant to health care quality; and (3) exchange electronic health information with, and integrate such information from other sources.( Article 13 of Title 15-Health Information Technology And Quality).

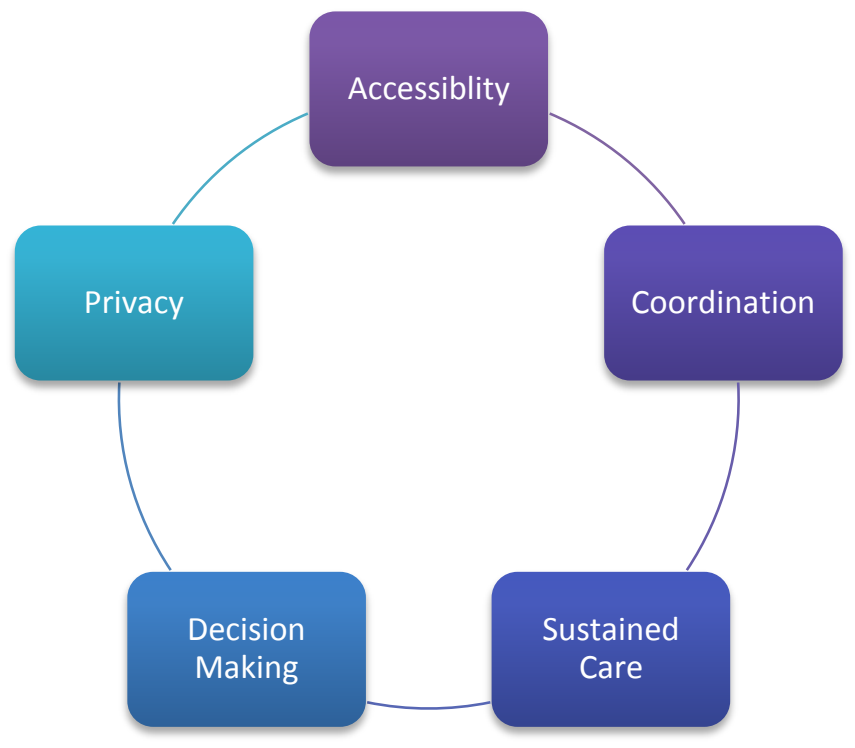

Figure 1. The Aspects of EHR Law.

\subsection{Accessibility}

Before exploring the patient's access to EHR in US legal system, it should be kept in mind that access to health information is highly regulated by American law. The HIPAA limits the access to the Protected Health Information (PHI). In the EHR context, the HIPAA defines PHI as including all medical, social, demographic, laboratory, imaging, and other data in the EHR systems. The US legal system carries civil and for some forms of violation, criminal penalties for individuals who break them, as well as sanctions and penalties for institutions that fail to protect health and personal information. Although the PHI information is protected from the general public, the patient should be granted access to EHR for the reason that generally patients must have access rights to their whole medical history, i.e. to all data any doctor has about them on file (Stephanidis, 2005). However, both the HIPPAA and the HITECH fail neither to accord concrete access rights to patients to EHR, nor to provide procedures over how the patient could practice the access out. In this context, the "Blue Button" was introduced in 2010 in the US to provide patient access to records through the Department of Veterans Affairs portal(Chelsom and Dogar, 2015). However, this remains as government guidelines, in place of a formal legislation or legislative amendment.

\subsection{Coordination}

In order to promote coordination, the HIPAA delegate the law enforcement agency the power to regulate (in the form of promulgating standards) coordination in the form of information transfer among the healthcare providers (Section 1173 of HIPAA). The standards would be promulgated "needed for the coordination of benefits". The rationale behind is that the clinicians need EHRs that can coordinate and track care delivery across all clinical settings (Krist, 2014), in order to better serve the interests of the patients.

In order to make the all the transfers traceable, the HIPAA mandates standards that provide for a standard unique health identifier for each individual, employer, health plan, and health care provider for use in the health care system should be further adopted (Section 1173.b.1 of HIPAA). These standards are also applicable in the PHI exchange in the EHR context.

\subsection{Sustained Care}

To promote sustained care, MU mandates that EHRs have reminders and generate registries. From the patient-centered 
perspective, the EHRs should, furthermore, need to allow patients to identify their clinicians. Also, clinicians are required to define and track their patient panel size. Also, according to Sheridan's analysis, for the EHR to achieve sustainability vis-à-vis the healthcare, the patients must be convinced that their security will be protected and are ensured the right to information. (Sheridan, 2012) (As shown in Figure 2). This is the reason why the HIPPA has put significant focus on protecting the PHI safety.
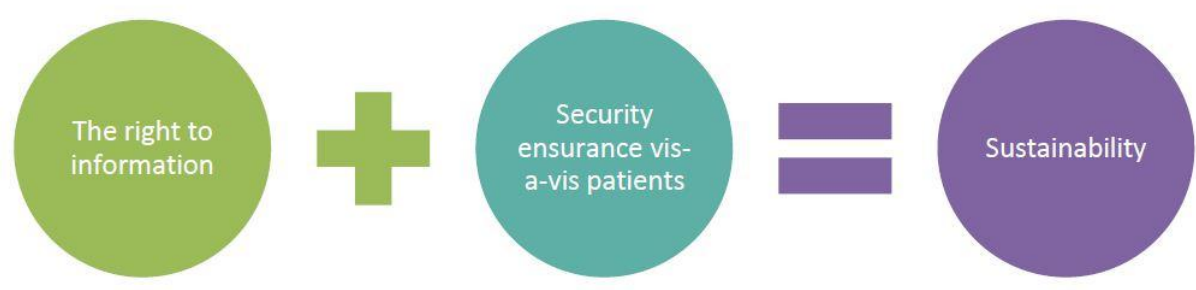

Figure 2. The Factors That Lead To Sustainability in Care

\subsection{Decision Making}

Electronic clinical decision making support systems (CDSSs) are systems that are designed to integrate medical information, patient information, and a decision-making tool to generate information to assist with cases (Niles 2014). The rationale behind is that care needs to be tailored to each individual through shared decision-making and patient and family engagement(Sheridan et al, 2004; Krist 2014). However, the law fails to mandate an EHR include decision support. In addition, the law also leave it unregulated that the record should capture and document a patient's readiness to change unhealthy behaviors and also appropriately provide tailed prompts and materials to clinicians, patients and families to better motivate and support change (Estabrooks, 2012).

\subsection{Privacy}

In place of directly providing requirement for privacy protection, the legislative system lists this theme as one of "specific areas of standard development". In its statutory wording, the HITECH Act regulates the EHR technologies should protect the privacy of health information and promote security. In more detailed atmosphere, it includes the segmentation and protection from disclosure of specific and sensitive individually identifiable health information with the goal of minimizing the reluctance of patients to seek care (or disclose information about a condition) because of privacy concerns, in accordance with applicable law, and for the use and disclosure of limited data sets of such information. U.S. law requires companies to inform individuals in the event of a data breach. Examining the law reveals that privacy breaches lead to punishment for the intruders, but not for the EHR maintainers. Nonetheless, as a limitation imposed to privacy, the U.S. legislation permits law enforcement access to EMRs, allowing sensitive health care information to be shared among government agencies without a warrant, a court order or the prior informed consent of the individuals involved.

\section{Discussion}

An understanding of the patient is central to creating long-term partnerships. The current system has capacities to perform drug-formulary checks, incorporate clinical laboratory results into EHRs, provide reminders to patients for needed care, identify and provide patient-specific health education resources, and employ EHRs to support the patient's transitions between care settings or personnel (Blumenthal and Tavenner, 2010). As a matter of fact, clinicians spend the majority of their time providing direct care to patients (Menke et al, 2001; Poissant et al, 2005) and hope that an EHR could increase this patient-interaction time and consequently the quality of care delivered (Leung et al, 2003; Poissant et al, 2005). In this context, the current system could be further improved from the following aspects:

First, A mandatory Adoption of EHR system. A non-uniform information system within the hospital system (paper-based in some units and electronic in others) may increase clinical hazards as patients move from one unit to another (Jha et al, 2009). The non-uniformity among American hospitals at this point could be explained by the fact that the US legal system fails to mandate a mandatory adoption of EHR system in its legal wording. As a result, the law should expressly mandate a adoption of EHR system. Moreover, it is recommended that the legislative system should further provide standards concerning what elements the EHR system should consist of. This could help standardize the EHR systems across the American hospitals.

Second, privacy should be further ensured. The concept of privacy is of vital significance and preoccupies human rights law (Wicks, 2007). The value of privacy is of so much importance that it has been recognized in international human rights law including inter alia the International Covenant on Civil and Political Rights (ICCPR). In the medical context, 
privacy to patient is of great relevance of human rights (Woogara, 2005; Faunce, 2005). However, in the EHR legal framework, the privacy protection is not given its true status as a fundamental human right. In this context, the legal system should give more attention to privacy. First, The Privacy Rule gives individuals the right to request that a covered entity correct any inaccurate PHI. Second, punishment arising from privacy breaches should be imposed against not only the intruders, but also the EHR maintainers, if the latter fails to act as a "good guardian".

Third The accessibility should be further improved. From the patient-centered perspective, is the clinician accessibility is also of great importance to providing satisfying medical service to the patients. To increase clinician accessibility, EHRs need to reduce documentation burden, help clinicians more beyond visits to deliver care, and allow clinicians to evaluate, monitor, and improve accessibility (Krist et al., 2014). From a legal perspective, this mechanism should not be left exclusively to the technicians. The law should instead provide the EHR system runner (in practice usually the healthcare provider) the obligation to reduce documentation burden. At this point, the legislative system could provide standards in its legal text. If EHRs could easily aggregate and accept structured clinical data from external sources, they might reduce documentation workload, allowing the clinician to be fully present for patient(Krist et al., 2014).

\section{Conclusion}

The main purpose of this paper was to make a study the patient empowerment elements of the regulations of the patient-centered health information technology in US. In 2009, only 17\% of US physicians use either a minimally functional or a comprehensive electronic records system. Although the situation is improving since after (Krist et al., 2014), there is still a lack of an up-to-date official data disclosed. The objective of this study is to investigate the effectiveness of the US's legal system of EHR. It also offers a cautionary note to practitioners, who are keen to develop and sell their health IT solutions, albeit now in an environment where privacy and security issues surroundinghealthdatapossiblyoutweighpastconsiderationsofcostreduction. Through the analysis of the above mentioned five aspects of the U.S. EHR system from the legal aspect, it is found that first, a mandatory adoption of EHR system; second, privacy should be further ensured; and third the accessibility should be further improved.

\section{References}

Blumenthal, D. (2009). Stimulating the adoption of health information technology. The New England Journal of Medicine, 360, 1477-1479.

Blumenthal, D., \& Tavenner, M.(2010). The "meaningful use" regulation for electronic health records. The New England Journal of Medicine, 363, 501-504

Buntin, M. B., Jain, S. H., \& Blumenthal, D. (2010). Health information technology: laying the infrastructure for national health reform. Health Affairs, 29(6), 1214-1219.

Chelsom J., \& Dogar, N. (2015). Patient Access to Their Health Record: Using Open Source HER. in: Courtney, K.L., Kuo, Shabestari, A.O. Driving Quality in Informatics: Fulfilling the Promise. IOS Press, p104

Ciampa, M., \& Revels, M. (2012).Introduction to healthcare information technology. Boston: Cengage Learning, 3-4.

Demiris, G., Afrin, L.B., Speedie, S., Courtney, K. L., Sondhi, M., Vimarlund, V., Lovis, C., Goossen, W., \& Cecil Lynch. (2008). Patient-centered applications: use of information technology to promote disease management and wellness. A White Paper by the AMIA Knowledge in Motion Working Group. Journal of American Medical Informatics Association, 15(1), 8-13;

Estabrooks, P. A., Boyle, M., \& Emmons, K. M. (2012). Harmonized patient-reported data elements in the electronic health record: supporting meaningful use by primary care action on health behaviors and key psychosocial factors. Journal of the American Medical Informatics Association, 19, 575-82.

Faunce, T. A. (2005). Pilgrims in medicine: conscience, legalism and human rights: an allegory of medical humanities, foundational virtues, ethical principles, law and human rights in medical, personal and professional development. Leiden: Martinus Nijhoff Publishers, 371-372;

Hiller, J., Matthew, S. M., Chumney, W. M., \& Baumer, D. L. (2011). Privacy and security in the implementation of health information technology (electronic health records): u.s. and eu compared. Boston University Journal of Science \& Technology Law, 17.

Jha, A. K., DesRoches, C. M., Campbell, E. G., Donelan, K., Rao, S. R., Ferris, T. G., Shields, A., Rosenbaum S., \& Blumenthal, D. (2009). Use of electronic health records in u.s. hospitals. The New England Journal of Medicine.

Krist, A. H., \& Woolf, S. H. (2011). A vision for patient-centered health information systems. Journal of American Medical Association, 305(3).

Krist, A. H., Beasley, J. W., \& Crosson, J. C. (2014). Electronic health record functionality needed to better support 
primary care. Journal of American Medical Association, 21, 764-771

Leung, G. M, Yu, P. L., Wong, I. O., Johnston, J. M., \& Tin, K. Y. (2003). Incentives and barriers that influence clinical computerization in Hong Kong: a population-based physician survey. The Journal of the American Medical Informatics Association, 10, 201-12;

Menke, J. A., Broner, C. W., Campbell, D. Y., McKissick, M. Y., \& Edwards-Beckett, J. A. (2001). Computerized clinical documentation system in the pediatric intensive care unit. BMC Medical Informatics and Decision Making, Massachusetts, Verenigde Staten, 1-3.

Niles, N. J. (2014). Basics of the U. S. Health Care System. Burlington: Jones \& Bartlett Publishers, 264

Poissant, L., Pereira, J., Tamblyn, R., \& Kawasumi, Y. (2005). The impact of electronic health records on time efficiency of physicians and nurses: a systematic review. Journal of the American Medical Informatics Association, 12(5), 505-516

Rittenhouse, D. R., \& Shortell, S. M. (2009). The patient-centered medical home will it stand the test of health reform? Journal of American Medical Association, 301(19).

Sheridan, S. (2012). The implementation and sustainability of electronic health records. Online Journal of Nursing Informatics, 16(3).

Sheridan, S. L., Harris, R. P., \& Woolf, S. H. (2004). Shared decision making about screening and chemoprevention: a suggested approach from the u.s. preventive services task force. American Journal of Preventive Medicin, 26, 56-66.

Stephanidis, C. (2005). Universal access in health telematics: a design code of practice. Berlin: Springer ,p286

Technology Advice. (2016). EHR buyer's guide: state of electronic medical records adoption. avaialbe at: http://technologyadvice.com/medical/ehr-emr/smart-advisor/

Wicks, E. (2007). Human Rights and Healthcare. London: Bloomsbury Publishing, 119-120

Woogara, J. (2005). Patients' privacy of the person and human rights. Nursing Ethics, 12(3), 273-287.

\section{$(\mathrm{cc}) \mathrm{BY}$}

This work is licensed under a Creative Commons Attribution 3.0 License. 